\section{(6) OPEN ACCESS}

\title{
Penile transplantation as an appropriate response to botched traditional circumcisions in South Africa: an argument against
}

\author{
Keymanthri Moodley, ${ }^{1}$ Stuart Rennie ${ }^{2}$
}

\begin{abstract}
${ }^{1}$ Department of Medicine, Centre for Medical Ethics and Law, Stellenbosch University, Stellenbosch, Western Cape, South Africa

${ }^{2}$ Department of Social Medicine, UNC Center for Bioethics, University of North CarolinaChapel Hill, Chapel Hill, North Carolina, USA
\end{abstract}

\section{Correspondence to} Professor Keymanthri Moodley, Department of Medicine, Centre for Medical Ethics and Law, Stellenbosch University, P.O. Box 2400, Cape Town, 8000, South Africa; km@sun.ac.za

Received 5 March 2016 Revised 23 September 2016 Accepted 9 June 2017 Published Online First 29 July 2017

Check for updates

To cite: Moodley K, Rennie S. J Med Ethics 2018:44:86-90.

\section{ABSTRACT}

Traditional male circumcision is a deeply entrenched cultural practice in South Africa. In recent times, there have been increasing numbers of botched circumcisions by untrained and unscrupulous practitioners, leading to genital mutilation and often, the need for penile amputation. Hailed as a world's first, a team of surgeons conducted the first successful penile transplant in Cape Town, South Africa in 2015. Despite the euphoria of this surgical victory, concerns about the use of this costly intervention in a context of severe resource constraints have been raised. In this paper, we explore some of the ethical implications of penile transplants as a clinical and public health response to the adverse consequences of traditional male circumcision. Given the current fiscal deficits in healthcare and public health sectors, how can one justify costly, high-technology interventions for conditions affecting a small section of the population? Since botched traditional male circumcisions are preventable, is a focus on penile transplantation as a form of treatment reasonable? Finally, do such interventions create undue expectations and false hope among a highly vulnerable and stigmatised group of young men? In this paper, we argue that given limited healthcare resources in South Africa and competing healthcare needs, prevention is a more appropriate response to botched traditional circumcisions than penile transplants.

\section{INTRODUCTION}

Every year in South Africa, as has probably been the case for centuries, young men undergo circumcisions as part of traditional rites of passage. However, over the past few decades there has been a reported rise of botched circumcisions leading to a number of complications, including penile amputation and death. ${ }^{1-3}$ Currently, it is estimated that roughly 250 traditional circumcisions lead to penile amputation every year in South Africa ${ }^{4}$; for 2015, there were 57 deaths during the summer circumcision season and 44 deaths during the winter season, ${ }^{5}$ and 27 initiates died during the summer of $2016 .{ }^{6}$ The South African government's official position is one of deep concern. The Ministry of Health has made it mandatory for traditional surgeons to register with the Department of Health. The Ministry of Co-operative Governance and Traditional Affairs has started to visit initiation schools and some arrests have been made. ${ }^{7}$ Despite these measures, traditional circumcisions by unqualified practitioners, some leading to permanent injury and death, continue unabated.
On 11 December 2014, a team of South African urologists and reconstructive surgeons at Tygerberg Hospital in South Africa performed what was hailed as the first successful penile transplant in the world on a 21-year-old victim of a botched traditional circumcision. ${ }^{8}$ While the long-term success of the operation remains to be seen, the patient's sexual function appears to have been restored, given that his girlfriend has reportedly become pregnant. ${ }^{9}$ Technically, however, this was not a first. In 2006, a penile transplant was conducted in Guangzhou, China. After the operation, the Chinese patient resumed normal urinary function, and there were no signs of infection or tissue rejection. However, 2 weeks later, the patient experienced significant psychological distress, and the transplant was reversed by the surgical team at the patient's request. ${ }^{10}$ More recently, reports emerged in the New York Times about proposed penile transplant surgery to be offered in the USA to wounded war veterans who suffered genitourinary injuries in Iraq and Afghanistan. ${ }^{4}$ On 8 May 2016, the first US penile transplantation took place with a patient with cancer in Massachusetts General Hospital. ${ }^{11}$ More recently, on 21 April 2017, the surgical team of Prof. Van der Merwe at Tygerberg Hospital conducted a second penile replacement operation. ${ }^{12}$ In our view, advances in penile transplantation in South Africa and elsewhere should not be an occasion for simple medical triumphalism. What significance does the ability to perform penile transplants have for young men in rural South Africa mutilated by traditional circumcision rites? In what follows, we will first present arguments in favour of promoting penile transplantation-including the use of public health funding-as a response to cases of severe penile injury in developed country settings. We will then present counterarguments and reasons for scepticism relative to the South African context.

\section{Promoting penile transplantation: reasons in favour}

An argument in support of penile transplantation starts from a recognition of the extensive physical and psychosocial suffering of men and boys with severe genitourinary injuries. Damage to the genital area can result in impairment of excretion, urinary incontinence, sexual dysfunction, hormonal imbalance and infertility. ${ }^{13}$ Those who have sustained penile injuries also commonly suffer from feelings of emasculation, suicidality and post-traumatic stress disorder. ${ }^{14}$ While penile transplantation (like 
its facial counterpart $)^{15}$ is life-enhancing rather than life-saving, successful transplantations could nevertheless substantially improve quality of life. In countries like the USA, three key beneficiary groups stand out: wounded military personnel, patients with cancer, accident victims and transgender men.

In the case of soldiers wounded in war, one could argue that the government has a clear obligation to support penile transplantation experimentation and successful interventions that result. This would presumably fall under a government obligation to provide compensation to those wounded during service for their country. The special obligation would be based on reciprocity, that is, veterans with genitourinary injuries should be cared for in exchange for the sacrifices they made in the line of duty. This obligation is stronger in regard to a conscription army where soldiers are coerced to fight and risk injury, but a reciprocity-based obligation to provide healthcare also remains in force in the case of volunteer armies. ${ }^{16}$ Further, this kind of obligation cannot be fulfilled by providing any sort of compensation. As Nancy Jecker puts it: "We cannot give reparation for the loss of a leg by providing a soldier with a financial bonus, better housing, or an expensive car. Reparation instead requires that we provide benefits, such as prosthetic devices and physical therapy, designed to make the soldier whole, i.e., to restore the soldier as much as possible to the state that existed prior to the injury." ${ }^{17}$ The special relationship of reciprocity yields at least a prima facie obligation on the part of government to provide penile transplantation for injured soldiers who meet medical and other criteria for the intervention.

A similar obligation could be extended to civilians suffering penile injuries due to non-battlefield causes, such as cancer or accidents, as with the patient in Boston. In this case, however, the basis of the obligation would have to change from reciprocity to a putative right to healthcare. Following Matthew Liao, one could argue for a right to basic healthcare, and then add further arguments to cover a further right to more-than-basic healthcare, including penile transplantation. Liao argues: (1) human beings have human rights to the fundamental conditions for pursuing a good life; (2) basic health is a fundamental condition for pursuing a good life; (3) therefore, human beings have a human right to basic health; (4) a human right to basic health implies a human right to those essential resources for maintaining and promoting basic health; (5) basic healthcare is an essential resource for maintaining and promoting basic health; (6) therefore, there is a human right to basic healthcare. ${ }^{18}$ The further step, that is, whether human beings with disabilities have rights to more than just basic healthcare, has long been discussed, without consensus. ${ }^{19}$ Defence of such rights leads quickly into questions of healthcare resource allocation, where under many cost-effectiveness models those with pre-existing disabilities often have less claim to medical care than the non-disabled. In many cases, getting the greatest benefit from scarce medical resources means providing them to those who are (healthwise) less worse off. Against this background, the ingredients for an argument for a right to penile transplantation in the US context would include: the fact that relatively few people would demand it; that the costs of the operation are likely to go down as techniques improve; that private insurance companies may provide coverage in the future. Many problems remain, clearly, such as weighing a right to penile transplantation against rights related to other, difficult-to-compare and more life-threatening forms of disability. However, that is true of all such rights.

Further, penis transplants are already stirring interest within the transgender community. ${ }^{20}$ For the first time, gender reassignment surgery could provide those born biologically as women but who experience themselves as men with a functional penis. The surgical procedures will be riskier and more complex than other cases, due to the transplant being preceded by extensive urethral reconstruction, reconstruction of the scrotum and removal of the vagina. Arguments in favour of supporting and promoting penis transplantation here are unlikely to be based on reciprocity or disability, but rather human rights to (sexual) health. The surgical alignment of genital anatomy with gender identity would have to be regarded not as cosmetic or as a form of enhancement, but as fundamental to the well-being of transgender men.

If penile transplantation proves safe and effective, no doubt it will be gradually integrated within healthcare systems in developed countries. No doubt, too, this will be accompanied by ethical challenges, as some have already pointed out. ${ }^{21} 22$ These include: risks of the procedure, including physical risks such as cancer and death-as has been the case with the first facial transplant patient on life-long immunosuppression, ${ }^{23}$ as well as psychosocial risks; enhanced consent processes including information on risk of graft failure and need to take immunosuppressant drugs for life; need to explicitly inform potential organ donors and family members of donors of the possibility of genital donation; responsible inclusion of first recipients in early penis transplant trials; provision of long-term postoperative psychosocial support; and last but not least, increasing equitable access to what will initially be a prohibitively expensive intervention, like other vascularised composite allotransplantation procedures. ${ }^{24}$

In short, ethical reasons can be given to support and promote penile transplantation as an innovative surgical procedure in a context like the USA. Our question, however, is what significance penile transplantation has for less well-resourced settings, with struggling healthcare systems, and with relatively high incidence of genitourinary injuries, such as South Africa.

\section{Traditional male circumcision in South Africa and government obligations}

As mentioned above, the population most in need of penile transplantation in South Africa are young male victims of botched circumcisions rather than wounded military personnel, the victims of accidents or cancer or transgender men. We will argue that the ethical reasons for pursuing penile transplantation for this population are weaker than in the case of more resourcerich countries, and the focus in South Africa should be firmly on measures to prevent botched circumcisions from happening in the first place.

But before staking this position, let us examine an important objection. Namely, one could argue, on the basis of liability, that the South African government has a responsibility to provide a high standard of care for victims of botched traditional circumcisions. The ill effects of traditional male circumcision in South Africa is not new. The results of research studies and calls for reform of traditional practices have been in the public domain for a number of years. If those at the South African Ministry of Health knew about the science, they are culpable for inaction; if they were ignorant of the science, this is culpable ignorance. Knowledge of health affairs is their job. Assuming the state has a responsibility to protect the health of their citizens, then the government has failed to prevent botched circumcisions from happening. Having failed in their duty to protect, they owe healthcare to victims of penile amputation, and more specifically, penile transplantation once it is demonstrated to be safe and effective.

The objection has some merit, but government responsibility in this case is more diffuse and less robust than the argument 
suggests. Deaths and injuries of circumcision initiates was never a serious concern for the Apartheid government, as these took place in the 'homelands' (or Bantustans) to which Blacks were assigned under the former regime. After the first democratic elections in 1994, governmental regulation of traditional male circumcision became a contentious political issue, particularly after the Eastern Cape provincial government passed the Application of Health Standards in Traditional Circumcision Act of 2001, provisions of which were regarded by traditional leaders as violations of cultural rights. ${ }^{25}$ In years 2001-2006, circumcision-related complications and fatalities remained virtually unchanged in the province, at least partly due to the views among some traditional leaders that all government interference in the ritual are undesirable. ${ }^{26}$ In response, the Ministry of Cooperative Governance and Traditional Affairs is currently crafting new national legislation, based on the Draft Policy of the Customary Practice of Circumcision in South Africa (2015). ${ }^{27}$

While legislative reform and enforcement efforts are welcome, recent studies indicate that botched circumcisions and indifference to legal prohibitions strongly reflect socioeconomic circumstances. Traditional male circumcision in South Africa has increasingly become a for-profit business in a context of deprivation and high unemployment. Licensed traditional surgeons at registered initiation schools charge more than 300 rand (US\$20) per initiate. In some communities, where there is substantial social pressure for young men to be circumcised, those who cannot afford legalised traditional services often turn to cheaper, non-registered schools and illegal (often quite young) practitioners. ${ }^{28}$ There are even reports of circumcision schools being operated like crime syndicates, where drug abusers are hired by kingpins to recruit boys for circumcision without their parent's knowledge or consent, and where ransom letters are issued to parents demanding money for their safe return. ${ }^{29}$ Many botched circumcisions stem from a conflict between the imperatives of tradition on the one hand, and the pressures of poverty on the other.

In short, responsibility for initiation deaths and injuries is shared by a number of key stakeholders: the government, traditional leaders, those who run circumcision schools and traditional practitioners involved in the act of circumcision and follow-up care, parents, police and community members. It is not clear that the South African government is solely at fault to prevent penile amputations due to botched circumcisions, nor (on grounds of liability, at least) that they owe penile transplantation to victims of botched circumcisions once the procedure is proved safe and effective. Of course, one could argue for governmental obligations on alternative grounds, such as the human right to health. But this would not distinguish penile transplantation from many other needed health interventions in South Africa to which the majority do not have access.

\section{Significance of penile transplantation for South Africa}

What does the ability to successfully transplant a penis mean in South Africa? Should the government support and promote the procedure by funding further research on the intervention and striving to integrate it into local health systems? We will argue that, at this juncture, this approach would be largely wasteful, ineffectual from a public health perspective and even in some ways harmful.

\section{Unjustifiable cost}

As mentioned, current costs of a penile transplant are extremely high. According to Andre Van der Merwe, the urologist who led the team that performed the penile transplant in South Africa, the total cost for the first month was estimated at 243000 rand (US\$17500) and approximately 16000 rand per month (US\$1150) for immunosuppression for the first 3 months after the operation (Andre Van der Merwe, personal communication, 2015). Immunosuppression is, however, lifelong and amounts to at least US\$14000 per year.

Expenditures on penile transplants in resource-depleted settings must be contextualised. According to World Bank data (2013), South Africa has a gross domestic product of approximately US $\$ 350$ billion of which $9.1 \%$ is spent on healthcare, less than half the US expenditure on healthcare. The per capita income in South Africa is US\$12240, and per capital healthcare expenditures of South Africans, according to the WHO and OCED (2014), is US\$981. These numbers must then be disaggregated by racial/ethnic groups, particularly groups in rural areas most likely to be subject to botched circumcisions. The out-of-pocket costs of penile transplants are therefore likely to far exceed the means of those most likely to need one. This population is also highly unlikely to have health insurance or be financially supported by non-profit organisations for this purpose. In addition, according to Beth Engelbrecht (Director of Health, Western Cape) at an address to the Faculty of Medicine and Health Sciences at Stellenbosch University, there is a predicted national deficit of close to 10 billion rand (US\$787 million) for health for the 2015-2016 financial year. For this reason, government allocation of funds for penile transplants would be very hard to ethically justify in the light of other pressing health priorities affecting vast numbers of vulnerable South Africans, notably HIV/AIDS, tuberculosis, interpersonal violence, cerebrovascular disease and heart disease. ${ }^{30}$

\section{Unrealistic standard of care}

One might argue that new medical technologies are always expensive at first, but over the course of time, they become a normal part of the local standard of care. For example, antiretroviral treatment was astronomically expensive when first introduced in the 1990s, and inaccessible to the millions of HIV-positive people who needed it in low-income countries. After advocacy, concessions by pharmaceutical companies and the rise of generic drugs, the prices of antiretroviral treatment dropped, saving the lives of millions of patients around the world. Who is to say that the same evolution will not happen with penile transplants?

However, this argument has a number of shortcomings. It is first worth noting that in the case of antiretroviral treatment, it has taken two decades to provide just partial coverage to those who need it, particularly in low-resource settings. ${ }^{31}$ Second, unlike antiretroviral treatment, penile transplant surgery is more demanding in terms of consuming healthcare infrastructure and resources. The better analogy would be with other surgeries or transplants. To what extent have (for example) heart surgery or lung transplants become standard of care for patients, particularly those less well off, in southern Africa?

Access to cardiac surgery in sub-Saharan Africa is known to be extremely low. According to Maribel et al, the ratio of cardiac surgery centres to patients is 1:33 million, excluding South Africa. ${ }^{32}$ While South Africans have relatively greater access to cardiac surgery than other Africans, much of the cardiac surgery takes place at expensive private clinics. To take another example, the first successful kidney transplant was performed at Boston's Bingham Hospital in 1954. Sixty years later, access to kidney transplants in sub-Saharan Africa remains highly restricted, with the majority of African countries having no facilities to provide transplants at all. ${ }^{33}$ In addition, cardiac surgery and kidney transplants are potentially life-saving interventions; the idea 
that penile transplants might become 'standard of care' in Africa seems far-fetched.

\section{Potential for destructive hope}

What effects are likely when a new successful medical intervention takes place, is publicised heavily in the media, but is highly unlikely to become the local standard of care anytime soon or ever? While answering this question will require robust social science research, it is reasonable to believe that the news will not be received with indifference among young men who have been maimed in circumcision rites, their partners and their families. With approximately 250 traditional circumcisions resulting in penile amputation a year, South Africa has a huge backlog of young men who would give anything to have a penile transplant. This desperation compounds their vulnerability. At the same time, there are also many foreign women in South Africa who may want or need reversal of female genital mutilation procedures that were conducted in other African countries. In the context of a public health system that is often failing to meet the needs of ordinary patients with common ailments, can needed procedures for non-life-threatening conditions be provided on an equitable basis? Medical advances that open exciting new treatment opportunities in one context can open a floodgate of futile expectation in another.

\section{Prevention versus treatment}

Given our argument in the previous sections, it seems more reasonable to continue to pursue prevention efforts to minimise the incidence of botched male circumcision rather than concentrate on penile transplantation as a therapeutic intervention. In South Africa, it is not clear that the medical profession has embarked on an extensive and effective process of community engagement and community consultation with respect to traditional male circumcision. Many questions are currently unanswered. What level of collaboration currently exists between the modern medical establishment and traditional practitioners? What circumstances tend to lead to botched male circumcisions? What legal mechanisms can be effectively employed to deter traditional practitioners from unsafe practices or effectively sanction those who are responsible for injuries or deaths?

Increased calls to alter traditional male circumcision practices have come from another quarter, namely in initiatives to circumcise men in sub-Saharan Africa for HIV prevention purposes. Voluntary medical male circumcision (VMMC) and traditional circumcision clearly have different purposes, procedures and meanings. Some traditional communities are resistant to joining forces with VMMC programmes, because the latter medicalises the rite of circumcision through the use of using modern surgical instruments and anaesthetics, and having medical officer oversight. Nevertheless, traditional practitioners and the South African government and medical establishment must continue to forge a durable compromise between honouring traditional values and ensuring the safety of initiates. With approximately 35 traditional male circumcision deaths per year and approximately 250 penile mutilations per year, it is obvious that there is a long way to go, yet this-rather than investing resources in penile transplantation technology-is the only reasonable path.

\section{CONCLUSION: HISTORY REPEATING ITSELF}

The successful penile transplantation in South Africa was new and exciting. But unfortunately, on reflection, it is part of an old and familiar pattern. In developed countries, health problems are often regarded from a strongly biomedical perspective, and high-technology biomedical interventions are developed to resolve them.
Those technologies are then typically exported (to some extent) to developing countries, where usually only a tiny socioeconomic elite is able to enjoy their benefits. Developing low-technology, preventive and potentially more equitable approaches to health problems is apparently less interesting (also financially) than producing the 'the next new treatment' through research and development. The case of penile transplantation brings the shortcomings of this long-established pattern into sharp relief. Botched circumcisions are a social problem, not just a medical problem, and, for reasons of effectiveness and ethics, need to be treated as such.

Contributors KM conceived the idea for the article and drafted the first version. SR contributed to the article and edited all subsequent versions. Both authors conducted a literature search and contributed equally to the final version.

\section{Competing interests None declared}

Provenance and peer review Not commissioned; externally peer reviewed.

Open Access This is an Open Access article distributed in accordance with the Creative Commons Attribution Non Commercial (CC BY-NC 4.0) license, which permits others to distribute, remix, adapt, build upon this work non-commercially, and license their derivative works on different terms, provided the original work is properly cited and the use is non-commercial. See: http://creativecommons.org/ licenses/by-nc/4.0/

(c) Article author(s) (or their employer(s) unless otherwise stated in the text of the article) 2018. All rights reserved. No commercial use is permitted unless otherwise expressly granted.

\section{REFERENCES}

1 Mogotlane SM, Ntlangulela JT, Ogunbanjo BG. Mortality and morbidity among traditionally circumcised Xhosa boys in the Eastern Cape Province, South Africa. Curationis 2004:27:57-62.

2 Wilcken A, Keil T, Dick B. Traditional male circumcision in eastern and southern Africa: a systematic review of prevalence and complications. Bull World Health Organ 2010;88:907-14

3 Khumalo S. South African boys dying to become men through traditional circumcision. The Telegraph 2009 http://www.telegraph.co.uk/expat/expatnews/ $6827077 /$ South-African- boys-dying-to-become-men-through-traditionalcircumcision.html

4 Kuehn BM. US hospitals prepare for penis transplants. JAMA 2016;315:1322-4.

5 The SA Government, Department of Traditional Affairs. Traditional Affairs on winter initiation season. 2016 http://www.gov.za/speeches/deputy-minister-obed-bapelawinter-initiation-season-2-jun-2016-0000

6 South African Broadcasting Corporation. 27 die through botched circumcision this year: government. 2016 http://www.sabc.co.za/news/a/cdb716004d8d $1707 \mathrm{a} 88 \mathrm{dec} 4 \mathrm{bb} 456 \mathrm{f3} \mathrm{b} / 27$ undefineddieundefinedthroughundefinedbot chedundefinedcircumcisionundefinedthisundefinedyear:undefinedGovernment20161907

7 Essop R. 'Unscrupulous' initiation school operators brought to book: Eyewitness news, 2015. http://ewn.co.za/2015/08/26/Unscrupulous-initiation-school-operatorsbrought-to-book

8 Bateman C. World's first successful penis transplant at Tygerberg Hospital. S Afr Med J 2015; 105:251-2.

9 Smith D. Penis transplant patient to become a father: The Guardian, 2015. http:// www.theguardian.com/world/2015/jun/12/penis-transplant- patient-partnerpregnant-south-africa

$10 \mathrm{Hu} \mathrm{W}$, Lu J, Zhang L, et al. A preliminary report of penile transplantation. Eur Urol 2006;50:851-3.

11 Grady D. Cancer survivor receives first penis transplant in the United States: New York Times, 2016. http://www.nytimes.com/2016/05/17/health/thomas-manning-firstpenis-transplant-in-us.html?_r=0

12 Akwei I. World's third penis transplant has been successfully performed on a 40-year-old man in South Africa by doctors from Stellenbosch University (SU) and the Tygerberg Academic Hospital in Cape Town. 2017 http://www.africanews.com/2017/ 05/23/world-s-third-penis-transplant-successfully-done-in-south-africa// (accessed July 2017).

13 Han JS, Edney MT, Gonzalez CM. Genitourinary Trauma in the Modern era of Warfare. J Mens health 2013;10:124-8

14 Lucas PA, Page PR, Phillip RD, et al. The impact of genital trauma on wounded servicemen: qualitative study. Injury 2014:45:825-9.

15 Khalifian S, Brazio PS, Mohan R, et al. Facial transplantation: the first 9 years. Lancet 2014:384:2153-63.

16 Selgelid MJ. Just liability and reciprocity reasons for treating wounded soldiers. Am J Bioeth 2008;8:19-21.

17 Jecker NS. Just healthcare for combatants. Am J Bioeth 2008;8:13-14.

18 Liao SM. Health (care) and human rights: a fundamental conditions approach. Theor Med Bioeth 2016;37:259-74. 


\section{Clinical ethics}

19 Bickenbach J. Zalta EN, "Disability and Health Care Rationing", The Stanford Encyclopedia of Philosophy. Edition, 2016. http://plato.stanford.edu/archives/spr2016/ entries/disability-care-rationing/

20 Kabas M. Doctors can now transplant penises. what does this mean for transgender men?Fusion, 2016:17. http://fusion.net/story/303034/penis-transplants-andtransgender-men/

21 Caplan AL, Kimberly LL, Parent B, et al. The Ethics of Penile Transplantation: Preliminary Recommendations. Transplantation 2017;101:1200-5.

22 Zhang LC, Zhao YB, Hu WL. Ethical issues in penile transplantation. Asian J Androl 2010:12:795-800.

23 Samuel H. World's first face transplant recipient Isabelle Dinoire dies of cancer: The Telegraph, 2016. http://www.telegraph.co.uk/news/2016/09/06/worlds-first-facetransplant-recipient-isabelle-dinoire-dies-of/

24 Murphy BD, Zuker RM, Borschel GH. Vascularized composite allotransplantation: an update on medical and surgical progress and remaining challenges. J Plast Reconstr Aesthet Surg 2013;66:1449-55.

25 Behrens KG. Traditional male circumcision: balancing cultural rights and the prevention of serious, avoidable harm. S Afr Med J 2013;104:15-16.
26 Meissner O, Buso DL. Traditional male circumcision in the Eastern Cape--scourge or blessing? S Afr Med J 2007:97:371-3.

27 South African Government News Agency. Cabinet gives green light to new initiation policy. 2016 http://www.sanews.gov.za/south-africa/cabinet-gives-green-light-newinitiation-policy

28 Douglas $M$, Hongoro C. The consideration of socioeconomic determinants in Prevention of traditional male circumcision deaths and complications. Am J Mens Health 2016.

29 Nkwashu G, Sifile L. Paid to recruit boys: Sowetan, 2015. http://www.pressreader. com/south-africa/sowetan/20150713

30 Pillay-van Wyk V, Msemburi W, Laubscher R, et al. Mortality trends and differentials in South Africa from 1997 to 2012: second National Burden of Disease Study. Lancet Glob Health 2016:4:e-642-0.

31 UNAIDS. Access to antiretroviral therapy in Africa. Status Report on Progress towards the 2015 targets. $2013 \mathrm{http}: / / w w w . u n a i d s . o r g / e n / r e s o u r c e s / d o c u m e n t s / 2013 /$ 20131219_AccessA RTAfricaStatusReportProgresstowards2015Targets

32 Mirabel M, Grimaldi A, Freers J, et al. Access to cardiac surgery in sub-Saharan Africa. Lancet 2015:385:606.

33 Naicker S. End-stage renal disease in Sub-Saharan Africa. Kidney Int Supp/ 2013;3:161-3. 